\title{
Value-Based Insurance Design: A "Clinically Sensitive, Fiscally Responsible" Approach to Mitigate The Adverse Clinical Effects of High-Deductible Consumer-Directed Health Plans
}

\author{
A. Mark Fendrick, $M D^{7}$ and Michael E. Chernew, $P h D^{2}$
}

'Departments of Internal Medicine and Health Management and Policy, University of Michigan, 300 North Ingalls Bldg., Room 7E06, Ann Arbor, MI 48109-0429, USA; ²Department of Health Care Policy, Harvard Medical School, 180 Longwood Ave., Boston, MA 021 15, USA.

DOI: $10.1007 / \mathrm{s} 11606-007-0188-2$

(C) 2007 Society of General Internal Medicine 2007;22:890-891

$\mathrm{T}$ here is no dispute that high deductible, consumerdirected health care (CDHC) plans are on the leading edge of market-based health insurance reform. The goal of these lower-priced health plans is to induce individuals to be more cost-conscious when consuming care, with the expectation that enhanced patient accountability will result in overall cost savings. Almost every available version of CDHC plans unwarrantedly connects the advantages of a better-informed patient population (a socially desirable outcome) to higher out-of-pocket expenditures for beneficiaries (uncertain desirability). This clear, yet avoidable, link between enhanced consumerism and increased cost sharing demonstrates a greater urgency for stakeholders to use CDHC plans more as a mechanism to constrain health care cost growth than as a tool to achieve improvements in access or quality of care.

We agree strongly with Woolhandler and Himmelstein's basic premise that high levels of patient cost sharing across all services will have deleterious clinical consequences, particularly for those with a preexisting medical condition and/or minimal disposable income. ${ }^{1}$

From a financial perspective, cost sharing approaches aim to control spending by making patients pay more at the point of service. Ideally, higher patient deductibles would discourage only the utilization of low-value care. For this important assumption to be achieved, patients must be able to distinguish between high-value and low-value interventions. However, when this ability to distinguish among services does not occur, increased cost sharing has an important negative component. A large and growing body of evidence demonstrates that, in response to increased cost sharing, patients decrease the use of life-saving interventions (e.g., immunizations, cancer screening, essential prescription drug use) and likely have worse health outcomes as a result. ${ }^{2-5}$ Thus, the alignment of clinical and financial incentives is a necessary component to insure the attainment of an efficient delivery system. The status quo has been unable to align quality

Published online April 6, 2007 improvement and cost containment initiatives. In fact, in some instances they actually compete with one another, contributing directly to inefficiency. ${ }^{6}$

In 2001, in response to the adverse clinical effects of "across the board" cost shifting - as is the case in CDHC plans - we proposed an approach to base a patient's out-of-pocket contribution on the value - not the cost - of the clinical intervention. ${ }^{7}$ This concept, now referred to as "value-based insurance design" [VBID], ${ }^{8,9}$ recognizes that the levels of evidence and the resultant value of various clinical services differ (e.g., screening for colon cancer compared to screening for ovarian cancer), and the value of any specific intervention varies across patient groups (e.g., colonoscopy for a 55-year-old with a firstdegree relative with colon cancer as compared to a low-risk 35year-old Today Show viewer). In this setting, cost sharing is still utilized, but in a "clinically sensitive" way, explicitly designed to mitigate the adverse health affects of high out-of-pocket expenditures. High-value services have no or minimal out-ofpocket costs; the converse is true for low-value services.

While there certainly are merits to greater individual autonomy in the purchasing of health care services, information gaps preclude informed decision making in many instances. A feasible way to attain the much needed financial effects of cost sharing and avoid the adverse clinical consequences of cost sharing would be to add an evidence-based "VBID waiver" to high deductible CDHC plans. This would entail that certain highly valued services be provided to beneficiaries with little or no out-of-pocket expense. Until the much-discussed information technology infrastructure is established in this country that will allow consumers better access to unbiased information of quality and cost of care, it is our view that purchasers, health plans, and policy makers insist that CDHC plans include safeguards against unwanted clinical effects that are directly related to misaligned financial incentives. While there is likely going to be considerable debate regarding the designation of high-value medical interventions eligible for copay relief, there are numerous services already identified by disease management programs, pay-for-performance initiatives, and health plan accrediting organizations such as the National Committee for Quality Assurance.

This CDHC/VBID approach may be viewed as "soft paternalism" to believers that the free market is already an efficient allocator of health care resources. From the financial perspective, this hybrid strategy may increase expenditures slightly compared to a standard CDHC plan, but at least the payer 
would be assured that these added costs were incurred for services of the highest clinical value, some of which may save money in the long term as a result of improved health outcomes.

While we agree with Woolhandler and Himmelstein's assertions that quality of care will be diminished and existing health disparities would be worsened under CDHC plans, especially for those with preexisting medical conditions, we differ on two fundamental points. First, we believe that higher levels of patient cost sharing will reduce medical expenditures. The Rand Health Insurance Experiment is among the many studies that demonstrate that when confronted with higher costs, individuals will purchase less care and in some cases, lower total expenditures. ${ }^{2}$ Published data are irrefutable that patient cost sharing is an effective mechanism to curtail the utilization of health care services. $^{3-5}$

Second, we believe a clinically nuanced benefit package can be crafted that is both high-quality and affordable. Our intent is not to argue that markets function better than government systems or vice versa. Regardless of the financing mechanism, a viable system must include an explicit approach to constrain health care cost growth. We believe that relying on clinically informed financial incentives - for patients and providers - will be useful in achieving improved health outcomes for any level of health care expenditures. Experience by both private and not-for-profit employers suggests that VBID programs can be implemented in a step-wise manner, subsidizing at first "lowlying fruit" such as preventive services and medications for diabetes mellitus and asthma. ${ }^{10}$ Ultimately, sophisticated information systems will tie together electronic medical records, clinical information (e.g., comparative effectiveness research, evidence-based guidelines, etc.), and financial data to create "personalized benefits" that encourage value and discourage waste. By using the available evidence base wisely and abandoning the archaic principle that each specific service must cost the same amount for all patients, regardless of clinical situation, we can move towards a health insurance benefit that is clinically effective and financially viable.

Corresponding Author: A. Mark Fendrick, MD; Departments of Internal Medicine and Health Management and Policy, University of Michigan, 300 North Ingalls Bldg., Room 7E06, Ann Arbor, MI 48109-0429, USA (e-mail: amfen@umich.edu).

\section{REFERENCES}

1. Woolhandler S, Himmelstein D. Consumer directed healthcare: except for the healthy and wealthy it's unwise. J Gen Intern Med. 2007; in press, DOI: $10.1007 / \mathrm{s} 11606-007-0187-3$.

2. Newhouse J, Insurance Experiment Group. Free for All? Lessons from the RAND Health Insurance Experiment. Cambridge, MA: Harvard University Press; 1993.

3. Gibson TB, Ozminkowski RJ, Goetzel RZ. The effects of prescription drug cost sharing: a review of the evidence. Am $J$ Manag Care. 2005; 11:730-40.

4. Rice T, Matsuoka KY. The impact of cost-sharing on appropriate utilization and health status: a review of the literature on seniors. Med Care Res Rev. 2004;61(4):415-52.

5. Heisler M, Langa KM, Eby EL, Fendrick AM, Kabeto MU, Piette JD. The health effects of restricting prescription medication use because of cost. Med Care. 2004;42:626-34.

6. Chernew ME, Rosen AB, Fendrick AM. Rising out-of-pocket costs in disease management programs. Am J Manag Care. 2006;12:150-4.

7. Fendrick AM, Smith DG, Chernew ME, Shaw SN. A benefit-based copay for prescription drugs: patient contribution based on total benefits, not drug acquisition cost. Am J Manag Care. 2001;7:861-7.

8. Fendrick AM, Chernew ME. Value based insurance design. A "Clinically Sensitive" approach to preserve quality and contain costs. Am J Manag Care. 2006; 1:18-20.

9. Chernew ME, Rosen AB, Fendrick AM. Value-based insurance design. Health Aff. 2007;26:w195-w203.

10. Freudenheim M. To save later, some employers are offering free drugs now. New York Times. February 21, 2007, A1. 